\title{
Audit of unexpected return visits to an accident and emergency department
}

\author{
P. S. WILKINS \& M. W. BECKETT \\ Accident E Emergency Department, West Middlesex Hospital, Isleworth, Middlesex \\ TW7 6AF
}

\section{SUMMARY}

Unscheduled re-attendances of patients to the A\&E Department were examined over 50 days. A re-attendance rate of 1.9 per 100 new patients was found. Of 102 return visits, only 35 resulted in no change in the diagnosis or treatment. Common faults in the initial consultation were failure to explain the condition and prognosis adequately and failure to provide adequate analgesia. Review of patients re attending unexpectedly by a more senior member of staff is a means of identifying faults in management and advising and educating junior staff.

\section{INTRODUCTION}

Audit of unanticipated return visits provides a means of assessing the quality of care in an A\&E department. There have been two recent studies of this problem, from the United States (Vertovec et al., 1990) and a recent study from the Leicester Royal Infirmary (Bodiwala \& O'Dwyer, 1991). The latter study found that many patients re-attending did not require further hospital treatment and concluded that many of these patients could equally well have been treated by their General Practitioners (GPs). We performed a study of patients re-attending the West Middlesex Accident Department to analyse the hypothesis that when a patient re-attends shortly after an initial visit, there is an implied failure of the initial consultation to diagnose, treat or explain the initial complaint adequately.

A prospective audit of all patients attending the A\&E Department at the West Middlesex University Hospital was started in December 1990. The West Middlesex serves a residential and light industrial urban area; there are 52000 new patient attendances and 6000 re-attendances, scheduled and unscheduled per annum. 


\section{PATIENTS AND METHODS}

Unanticipated return visits were identified by the receptionist and medical staff. There was no time limit and the only criteria for entry was that the patient felt their complaint to be related in some way to their initial presentation. A questionnaire was completed by the casualty officers and the notes were reviewed.

\section{RESULTS}

During the 50-day period of the study, there were 5811 new attendances to the A\&E Department, 650 scheduled re-attendances and 113 unscheduled re-attendances. The notes could not be traced for 11 of these re-attendances. Of the remaining 93 patients, nine re-attended unexpectedly on two occasions making 102 unexpected revisits for which the notes could be traced. The total of 113 gives a rate of 1.9 unscheduled re-attendances per 100 new patients seen. The unscheduled reattendances can be broken down into four groups which are shown in Table 1. The admission rate on re-attendance provides some measure of morbidity.

Over one third of all patients needed neither alteration to their treatment nor change in diagnosis (Group A). Analysis of these cases notes showed a few inevitable re-attendances such as the habitual drunk as well as a few patients told to come back for further assessment or investigation if their condition did not improve. The majority however ( 23 out of 34 re-attendances) appeared due to inadequate communication which took several forms illustrated as follows: (1) failure to explain unexpected duration of symptoms e.g. fractured toe (re-attended 3 weeks

Table 1. Changes in diagnosis or treatment on unscheduled re-attendance.

\begin{tabular}{llll}
\hline & $\begin{array}{c}\text { Number of patients } \\
\text { making a first } \\
\text { unscheduled } \\
\text { re-attendance }\end{array}$ & $\begin{array}{c}\text { Number of patients } \\
\text { making a second } \\
\text { unscheduled } \\
\text { re-attendance }\end{array}$ & $\begin{array}{c}\text { Number of patients } \\
\text { admitted }\end{array}$ \\
\hline Group A & $\begin{array}{l}\text { No change in diagnosis } \\
\text { or treatment }\end{array}$ & 34 & 0 \\
Group B & $\begin{array}{l}\text { No change in diagnosis } \\
\text { but change in treatment } \\
\text { needed because of } \\
\text { inadequate initial } \\
\text { treatment } \\
\text { Additional or different } \\
\text { diagnosis made } \\
\text { Change in treatment } \\
\text { made due to natural } \\
\text { progression of the } \\
\text { disease despite } \\
\text { adequate initial } \\
\text { treatment }\end{array}$ & 24 & 2 \\
Group D
\end{tabular}


later); (2) failure to provide adequate explanation or reassurance e.g. precordial catch (re-attended 2 days later); and (3) failure to explain or provide ongoing $\stackrel{\circ}{?}$ management by patient, e.g. dry dressing fell off (re-attended 2 days later), or by GP, e.g. cather washouts (re-attended 1 day later) Group B contains those patients inadequately treated despite a correct initial diagnosis. The commonest reason (11 re-attendances) was inadequate analgesia, usually for soft tissue injuries but including two patients with fractures. Morbidity was low, two patients being admitted with a urinary tract infection and post-operative infection respectively. Two patients who had not had pressure bandages applied had a recurrence of their cauliflower ear after aspiration.

Table 2 illustrates the third largest but most important group in terms of morbidity: those patients who had a different or additional diagnosis made on their re-attendance (Group $\mathrm{C}$ ). Only those requiring admission are shown in the table. Factors contributing to the incorrect diagnosis or confirming the subsequent diagnosis are indicated in the comments column. Of note is that two patients

Table 2. Different diagnosis made following return visit for which emergency admission was necessary (Group C).

Age Sex Diagnosis on 1st visit Diagnosis on 2nd visit Diagnosis on 3rd visit Comments

\begin{tabular}{|c|c|c|c|c|c|}
\hline & $\mathbf{F}$ & Renal Colic* (1) & Renal Colic & Biliary Colic 2 & $\begin{array}{l}\text { IVU not performed } \\
\text { Ultrasound }\end{array}$ \\
\hline
\end{tabular}

22 M Gastroenteritis (1) Epididymitis (2) Torsion testis (3)

48 M Asthma and non- COAD and myocardial cardiac chest pain (1) infarction (2)

19 M Viral gastritis Inflammatory polyp at ileocaecal junction*(1)

Testes not examined Not confirmed by urine testing Orchidectomy CXR, ECG normal

Blood gases Spirometry ECG and cardiac enzyme changes following admission 2 days after first visit

Made on colonoscopy after investigation of persistently raised ESR and temperature

14 F Urinary tract Haematocolpos* (2) infection (1)

Not confirmed on urine microscopy

One month after first visit

49 M Peptic Ulcer Ischaemic heart disease

Myocardial infarction unproven after ECG, cardiac enzymes and echocardiogram

\footnotetext{
* Indicates admission diagnosis: the diagnosis then given is the diagnosis on discharge.
} 
misdiagnosed as having epididymitis and urinary tract infection respectively did not have this confirmed by urine microscopy. Of the remaining 18 re-attendances, five had different diagnoses made which did not lead to a change of management. Five patients had additional diagnoses made which were related to their initial complaint. The most serious was a 93-year-old lady who re-attended twice before a pubis ramus fracture was diagnosed. She initially presented with a head injury following a fall. There were three more minor cases of patients re-attending with injuries undetected due to failure to extend the history and examination beyond the presenting complaint. The remainder of this group consisted of patients whose complaint on re-attendance turned out to be unrelated to their first, e.g. a child who swallowed a coin and returned 2 weeks later with gastroenteritis.

The final and smallest category (Group D) is of patients whose disease progressed despite reasonable initial management. Four of these were cases of mild asthma where management followed the British Thoracic Society (Brewis, 1990 a\&b) guidelines except that in two cases the timing of post-nebuliser peak flows was not documented indicating possible under-treatment. One asthmatic was admitted but did not receive intravenous therapy and there were four other admissions with viral bronchiolitis, biliary colic, threatened abortion and tension headaches following an overdose.

We looked at the nine patients who re-attended more than once to see whether routine review of attendances by a registrar or consultant may have prevented morbidity. Five of them did receive an opinion from the appropriate on-call registrar or the A\&E registrar or consultant. Of the remainder, two patients may have benefitted from a more senior opinion - one with grand mal seizures and the elderly lady with a missed pubic ramus fracture.

The mean time from initial presentation to unanticipated re-attendance was 8 days. The longest period was 92 days with a soft tissue injury to the hand.

A total of $47 \%$ of unexpected revisits were instigated by the patient. Thirty-five per cent had been told, at their first attendance, to return if their condition worsened, recurred or did not improve and $18 \%$ were referred by their GP. There were no deaths.

\section{CONCLUSION}

The unscheduled re-attendance rate of 1.9 per 100 new patients compares with the rate of $0.72 \%$ for the American study (Vertovec et al., 1990) which only looked at patients re-attending within $48 \mathrm{~h}$ of the initial visit. The Leicester study (Bodiwala \& O'Dwyer, 1991) found the rate of $2.9 \%$ re-attendances. The re-attendance rates of patients in an urban area may underestimate patient dissatisfaction since it is a simple matter to seek a second opinion from a different A\&E Department.

In $34 \%$ of unexpected reattendances there was no change in diagnosis or management and no worsening of the patient's condition. The majority of these could have been prevented had more time been spent in explaining the diagnosis, prognosis and appropriate further treatment to the patient.

The major area of potential improvement is in providing adequate analgesia 
for soft tissue and bony injuries; this would have prevented a third of the reattendances due to inadequate treatment despite a correct diagnosis.

Approximately $20 \%$ of unscheduled re-attendances had different or additional $\stackrel{?}{\Rightarrow}$ diagnosis made. This figure is similar to that found in the Leicester study if $\stackrel{\vec{\sim}}{\rightarrow}$ allowances are made for their greater number of overall re-attendances. This group accounts for the greatest avoidable morbidity. In only one of these cases, and in $\frac{\bar{\sigma}}{\bar{\omega}}$ one other case did failure to obtain a more senior opinion contribute to morbidity. $\vec{\varnothing}$ However, as a result of this audit we have introduced a policy whereby all patients unexpectedly re-attending are reviewed by the A\&E consultant or registrar with a view to identifying any deficiencies in initial management and advising the casualty officers accordingly.

Audit needs to be self-critical if it is to be useful. This study shows that when a $\frac{\mathscr{\Phi}}{\Phi}$ patient attends an A\&E Department a second time for the same complaint, then in 3 . the majority of cases (about $80 \%$ ) it is appropriate to attribute the re-attendance to deficiencies in the initial consultation.

\section{REFERENCES}

Bodiwala G. G. \& O'Dwyer F. (1991) Unscheduled return visits by patients to the A\&E Department. Ф Archives of Entergency Medicine 8(3), 196-200.

Brewis G. (1990a) Guidelines for the management of asthma in adults I. Chronic asthma. British Mediag Journal 301, 651-653.

Brewis G. (1990b) Guidelines for the management of asthma in adults II. Acute severe asthma. Britiș Medical Journal 301, 797-800.

Vertovec A. M., Feldman R. M., Cooper M. A. et al. (1990) Morbidity of patients with unscheduled return visits. Journal of Entergency Medicine 8(3), 377. 